\title{
HOT DUCTILITY BEHAVIOR OF A CONTINUOUSLY CAST Ti-Nb MICROALLOYED STEEL
}

\author{
${ }^{1}$ Christian HOFLEHNER, ${ }^{1}$ Coline BEAL, ${ }^{1}$ Christof SOMMITSCH, ${ }^{2}$ Jakob SIX, ${ }^{2}$ Sergio ILIE \\ ${ }^{1}$ Graz University of Technology, Graz, Austria, EU, office.imat@tugraz.at \\ ${ }^{2}$ voestalpine Stahl Linz GmbH, Linz, Austria, EU
}

https://doi.org/10.37904/metal.2019.673

\begin{abstract}
The hot ductility behaviour of a Ti-Nb micro alloyed steel was investigated to evaluate the probability of surface crack formation during the continuous casting process, by performing hot tensile tests. The testing temperatures are ranging from $1100{ }^{\circ} \mathrm{C}$ to $700{ }^{\circ} \mathrm{C}$. The effects of testing temperature range and deformation rate on hot ductility were investigated. The results show that this steel exhibits poor ductility over almost the whole testing temperature range. The ductility starts to decrease at $1000{ }^{\circ} \mathrm{C}$ in the single phase $\gamma$-region, characterized by grain boundary sliding and surface cracks, reaches a minimum in the two-phase $\alpha-\gamma-$ region at $750{ }^{\circ} \mathrm{C}$ and slightly increases with decreasing testing temperature. Furthermore, low deformation rates severely decrease the ductility behaviour. Microstructural examinations and supplementary thermo-kinetic computer simulations revealed distinct $\mathrm{Ti}-\mathrm{Nb}$ precipitation throughout the microstructure being responsible for the deteriorated materials hot ductility.
\end{abstract}

Keywords: Metallurgy, steel, continuous casting, hot ductility, low alloyed, testing methods

\section{INTRODUCTION}

In the straightening operation of the continuous casting process, high mechanical and thermal stresses are affecting the steel slab. Theses stresses may cause internal tears and surface cracks that lead to a loss of productivity and quality in the steelmaking process [1-3]. The sensitivity to transverse cracking of continuously cast steels can be primarily adressed to the poor ductility behaviour at a temperature range of $700{ }^{\circ} \mathrm{C}-1000^{\circ} \mathrm{C}$. The straitening operation takes place at these temperatures [4]. Poor ductility behaviour is caused by the strain concentraitions at the ferrite films along the austenite grain boundaries and precipitations. Ferrite, which is the lower strengh phase, prefers to form at the austenite grain boundaries and absorbs the majority of deformation. If the potential of ferrite to accommodate the strain is exeeded, poor ductulity values occur [5]. In the austenitic high temparture region, a high amount of fine precipitates are the main damaging mechanism. These precipitates can lead to local hardening and severe stress concentrations, which can trigger the nucleation of wege-type cavities that lead to interconnections of cavities surounding the precipitates [6].

The hot ductility can be evaluated by measuring the percentage reduction of area (RA) after fracture in a hot tensile test of samples, by using similar thermomechanical conditions [7,8]. To avoid transverse cracks, the RA value should exceed the limit of $40 \%$ [9]. To apply the thermomechanical conditions of continuous casting, in-situ melted and solidified specimens are used in the hot tensile test. This approach allows the dissolution and nucleation of precipitation, such as $(\mathrm{Ti}, \mathrm{Nb})(\mathrm{C}, \mathrm{N})$ and $\mathrm{MnS}$, which weaken the grain boundaries and considers the segregation of alloying elements $[10,11]$.

In this work, the hot ductility of a micro alloyed Ti-Nb steel was investigated in a temperature range of $600{ }^{\circ} \mathrm{C}$ to $1200{ }^{\circ} \mathrm{C}$ to predict the temperatures at which the hot ductility behaviour deteriorates.

\section{EXPERIMENTAL}

\subsection{Chemical composition}

The chemical composition of the investigated steel is given in Table 1. To obtain phase transformation temperatures, thermodynamic equilibrium calculations have been performed using the thermokinetic software 
MatCalc (version 6.02) [12]. The ferrite start temperature $\left(A_{e 3}\right)$ was found to be $837^{\circ} \mathrm{C}$ and the ferrite finish temperature $\left(A_{e 1}\right) 674^{\circ} \mathrm{C}$.

Table 1 Chemical composition of the investigated steel in wt $\%$

\begin{tabular}{|c|c|c|c|c|c|c|c|c|c|c|}
\hline $\mathrm{C}$ & $\mathrm{Cr}$ & $\mathrm{Mn}$ & $\mathrm{Nb}$ & $\mathrm{N}$ & $\mathrm{Ni}$ & $\mathrm{P}$ & $\mathrm{S}$ & $\mathrm{Ti}$ & $\mathrm{Al}$ & $\mathrm{Fe}$ \\
\hline 0.081 & 0.037 & 1.43 & 0.046 & $43 \mathrm{ppm}$ & 0.02 & 0.0096 & 0.0033 & 0.066 & 0.041 & bal. \\
\hline
\end{tabular}

\subsection{Hot tensile tests}

An in-house developed vertical thermomechanical simulator BETA 250-5 (Figure 1a) was used to conduct hot tensile tests. The experiments were performed in a vacuum atmosphere with a pressure of $0.2 \mathrm{mbar}$. Cylindrical tensile specimen (Figure 1b) were machined from the continuously cast and hot rolled billed with their axis parallel to the rolling direction. The upper end of the specimen was clamped to the tension arm which is responsible for the displacement in upwards direction. The lower end was clamped to a special extractor, which has a fixed position and is equipped with a spring and three gripper arms, which have three functions: they hold the sample when pulling it upwards, they compensate for the thermal expansion of the specimen and support it during the melting cycle of the temperature curve, so it doesn't break in this unstable experimental phase. A Pt/Pt-Rh thermocouple was spot-welded to the body center of the specimen to measure the surface temperature. An inductive heating system was used to perform the temperature cycle. The induction coil is physically linked with the tension arm and moves with half of the speed of the upwards displacement to ensure, that with ongoing deformation, the induction coil system stays positioned at the center of the specimen.

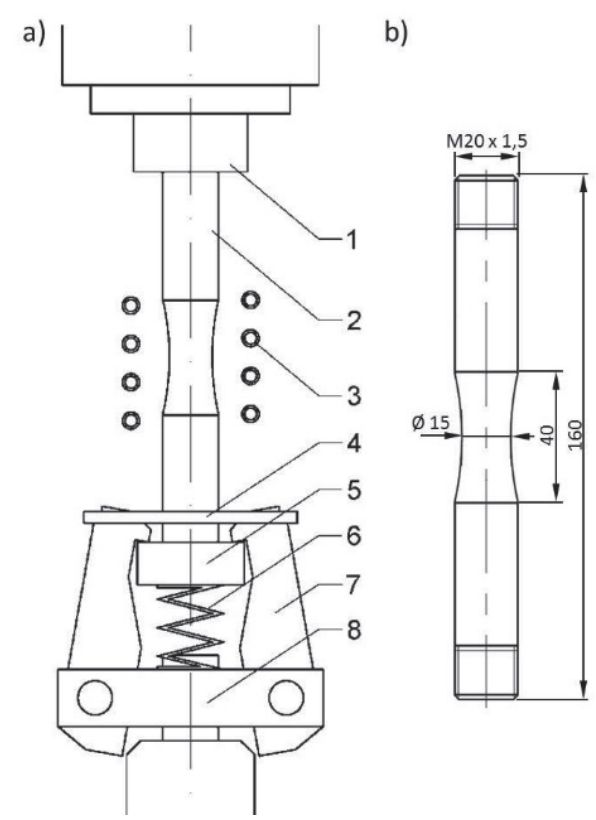

Figure 1 Tensile testing equipment "BETA 250-5" (1. tension arm, 2. tensile specimen, 3. induction coil, 4. securing ring, 5 . holding ring, 6 . steel spring, 7. gripper arm, 8. extractor unit); b) geometry and dimension of the tensile specimen in $\mathrm{mm}$ [13]

The temperature cycle for the experiment is shown in Figure 2. The measured surface temperature during the melting phase is $1445^{\circ} \mathrm{C}$, which was held for 60 seconds. The melting phase is followed by a first cooling phase with $5^{\circ} \mathrm{C} / \mathrm{s}$ till $1250^{\circ} \mathrm{C}$ and a second cooling phase with $1{ }^{\circ} \mathrm{C} / \mathrm{s}$ till the testing temperatures, which range from $1100^{\circ} \mathrm{C}$ to $600{ }^{\circ} \mathrm{C}$. As a standard the tensile tests were performed at a strain rate of $1 \times 10^{-3} / \mathrm{s}$. For each testing temperature, a total number of 3 samples were tested. To evaluate the hot ductility, the reduction of area was measured graphically by a stereo microscope. Metallographic analyses were carried out on 
longitudinal cross sections of ruptured specimen near the fracture surface using light optical microscopy (LOM) and scanning electron microscopy (SEM).

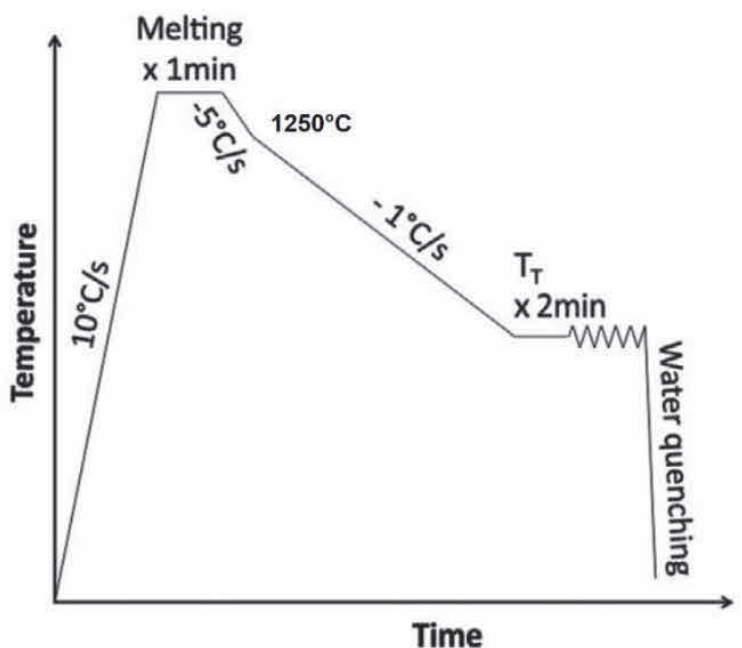

Figure 2 Temperature cycle for the experiment

\section{RESULTS}

\subsection{Hot ductility behaviour}

The hot ductility curve represented by the reduction of area as a function of the deformation temperature for the in-situ melted steel is shown in Figure 3 . The ductility minimum is at $750^{\circ} \mathrm{C}$ but the critical proposed RAvalue of $40 \%$ by Mintz is exceeded at a temperature range from $700{ }^{\circ} \mathrm{C}$ to $900{ }^{\circ} \mathrm{C}$. This critical value is displayed as a horizontal dashed line in Figure 3 . The ductility starts decreasing in the pure austenitic region with decreasing temperature, however below $700^{\circ} \mathrm{C}$ the ductility recovers.

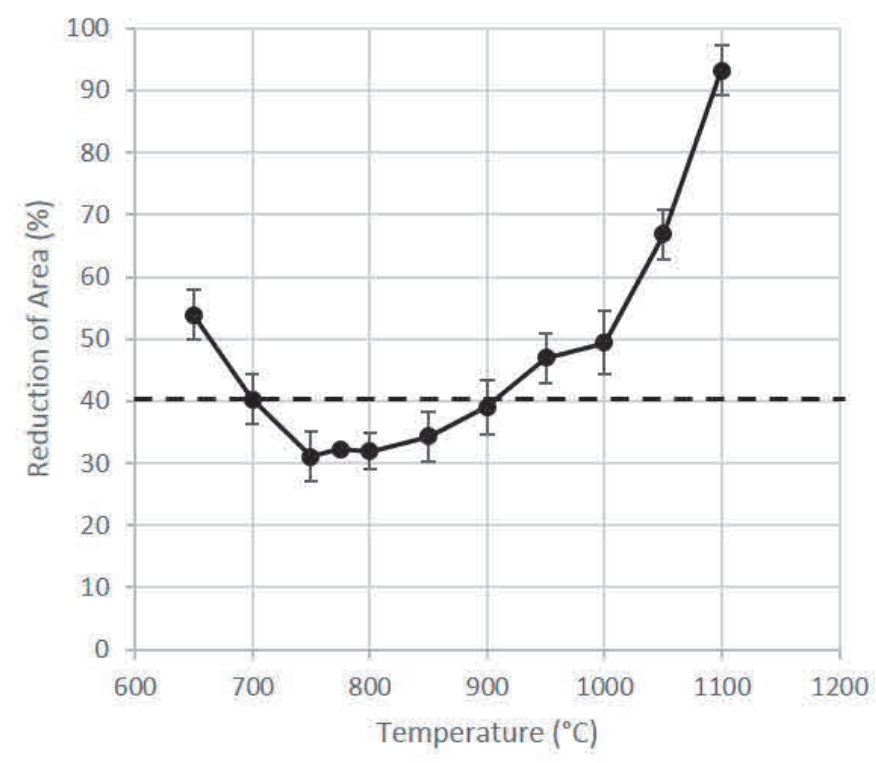

Figure 3 Hot ductility curve

\subsection{Metallography}

LOM images of water quenched specimens after pulling to fracture show a large number of cracks and pores, especially at temperatures between $750{ }^{\circ} \mathrm{C}$ to $1000{ }^{\circ} \mathrm{C}$ [15]. In specimens pulled at $900{ }^{\circ} \mathrm{C}$ and $800{ }^{\circ} \mathrm{C}$, the 
pores, which form preferably at the grain boundaries at the former austenite grains, are already interconnected and form cracks along the grain boundaries. In the specimen pulled at $775^{\circ} \mathrm{C}$ these cracks are elongated over multiple grain boundaries and a small amount of ferrite appears at the former austenite grain boundaries. At a deformation temperature of $700{ }^{\circ} \mathrm{C}$ however, we see the formation of ferrite and a smaller number of cracks and pores. Furthermore, primary precipitates are visible in all specimens. These precipitates are in the size of 1-10 $\mu \mathrm{m}$ and have been identified as primary $(\mathrm{Ti}, \mathrm{Nb})(\mathrm{C}, \mathrm{N})$ precipitates and MnS precipitates [15].

\subsection{Simulation of secondary precipitation}

Figure 4 shows the results of the precipitation kinetics simulation, which include the mean particle radii, the phase fraction and the number densities of $(\mathrm{Ti}, \mathrm{Nb})(\mathrm{C}, \mathrm{N})$ and $\mathrm{MnS}$ precipitates. Additionally, AIN is included in the simulation, but none is formed according to it. The initial temperature is $1471^{\circ} \mathrm{C}$ to simulate the continuous casting process. The subsequent heat treatment is the same as shown in Figure 2. The deformation temperature of the shown simulation is $800{ }^{\circ} \mathrm{C}$, where there is a very poor ductility behaviour. The simulated strain rate is $1 \times 10^{-3} / \mathrm{s}$, in accordance with the experiment. The initial grain size of the austenitic grain is set to $500 \mu \mathrm{m}$ and the nucleation sites are set to grain boundaries, dislocations and additionally $(\mathrm{Ti}, \mathrm{Nb})(\mathrm{C}, \mathrm{N})$ can nucleate on MnS precipitates. $(\mathrm{Ti}, \mathrm{Nb})(\mathrm{C}, \mathrm{N})$ starts nucleating at $1360^{\circ} \mathrm{C}$ mainly at dislocations and $\mathrm{MnS}$ at $1105^{\circ} \mathrm{C}$ at the grain boundaries. At a running time of $505 \mathrm{~s}$, the deformation starts severely increasing the number densities and phase fractions of the precipitations. Shortly after the deformation starts, a massive drop in the mean radius can be observed. This is due to the severe increase of new nucleated precipitates which can be seen in the increase in number density. After a few seconds, number density and mean radius are staying constant and so is the phase fraction.
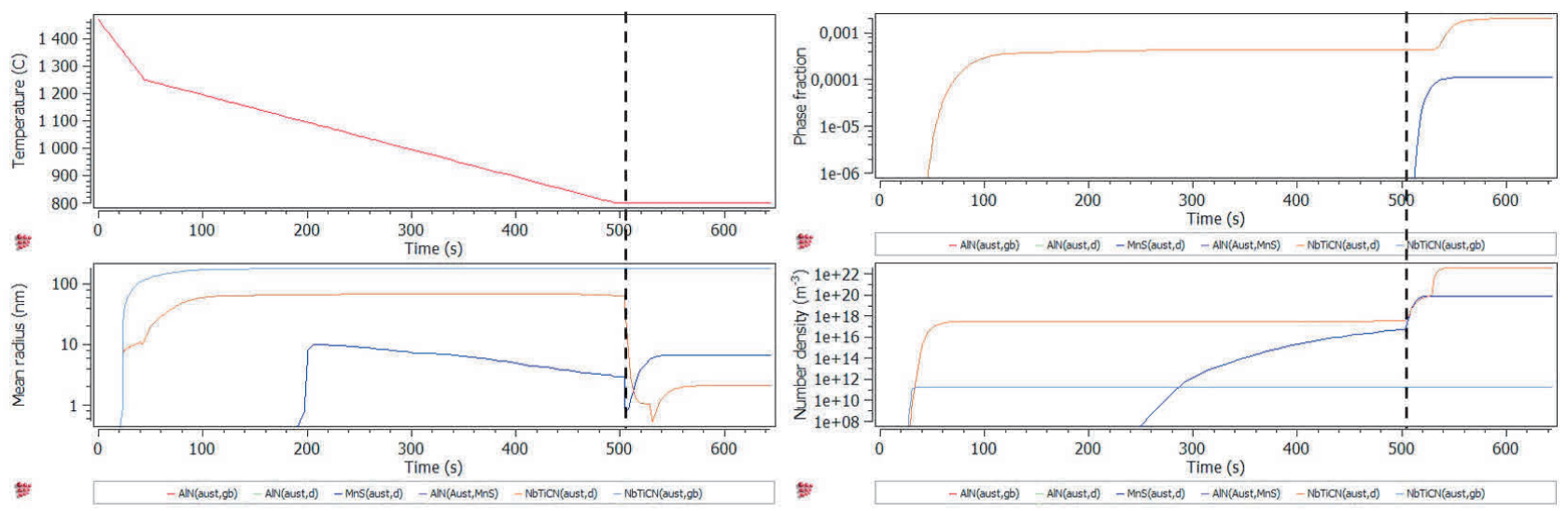

Figure 4 Calculated evolution of mean particle radius, phase fraction and number density of $(\mathrm{Ti}, \mathrm{Nb})(\mathrm{C}, \mathrm{N})$ and MnS precipitation during the cooling phase and the deformation temperature of $800{ }^{\circ} \mathrm{C}$

\section{DISCUSSION}

In the literature, two major mechanisms are described where the precipitates reduce the hot ductility in the austenitic region. Precipitates on grain boundaries favour the nucleation and interconnection of cavities around them. At low strain rates, the nucleation, growth and coalescence of voids around second phase precipitates lead to a poor ductility behaviour $[16,17]$.

The second mechanism describes the presence of fine precipitates at dislocations, which increases the strength of the grains due to dislocation pinning. Hence grain boundary sliding is hindered. Cavities form by the migration of vacant lattice sites into the triple point region of grain boundaries, where high stress concentrations occur. Wedge cracks are the result of accelerated linking of growing cavities leading to a poor ductility behaviour $[18,19]$. 
Both effects are causing the ductility drop in the austenitic temperature region. Lückl et al. [20] reported a similar behaviour in their experimental studies with steel grads with lower Ti-content compared to our investigated chemical composition.

The increase in ductility at lower temperatures can be attributed to the formation of sufficient ferrite and the suppression of the strain localization effect [9].

\section{CONCLUSION}

The hot ductility of an in-situ melted and solidified micro alloyed Ti-Nb steel was investigated. The region of poor ductility was found to be between $700{ }^{\circ} \mathrm{C}$ and $900{ }^{\circ} \mathrm{C}$, with a minimum at $750{ }^{\circ} \mathrm{C}$. This behaviour is the result of a high density of fine secondary precipitates $(\mathrm{MnS})$ at the grain boundaries and in the bulk at dislocations $((\mathrm{Ti}, \mathrm{Nb})(\mathrm{C}, \mathrm{N}))$ of the material. The recovery of the ductility at testing temperatures of $700{ }^{\circ} \mathrm{C}$ and below occurs due to sufficiently formed ferrite preventing intergranular stress concentrations.

\section{ACKNOWLEDGEMENTS}

The research program of K1-MET, which has been financially supported within the Austrian competence center program COMET by the Federal Ministry of Economy, Family and Youth; by the Federal Ministry for Transport, Innovation and Technology; by the provinces of Upper Austria, Styria, and Tyrol; by the Styrian Business Promotion Agency and by the Tiroler Zukunftsstiftung, has its focus on the modelling and simulation of metallurgical processes, including metallurgical raw materials and refractoriness with the goal of an optimal process control with respect to product quality, zero waste, and the minimization of energy and raw materials, is acknowledged.

\section{REFERENCES}

[1] ARIKAN, M. M. Hot Ductility Behavior of a Peritectic Steel during Continuous Casting. Metals. 2015, pp. 986-999

[2] DIPPENAAR, R., BERNHARD, C., SCHIDER S. and WIESER G. Austenite Grain Growth and the Surface Quality of Continuously Cast Steel. Metallurgical and Materials Transactions B, 2014. vol. 45, pp. 409-418.

[3] LANKFORD, W. T. Some Considerations of Strength and Ductility in the Continuous-Casting Process. Metallurgical Transactions B, 1972. vol. 3, pp. 1331-1357.

[4] CROWTHER, D. N. and MINTZ, B. Hot ductility of steels and its relationship to the problem of transverse cracking in continuous casting. International Materials Reviews, 2010. vol. 55( 3). pp. 168-196.

[5] MINTZ, B., LEWIS, J. and JONAS, J. J. Importance of deformation induced ferrite and factors which control its formation. Materials Science and Technology . 1997. vol. 13, pp. 379-388.

[6] MINTZ, B., YUE, S. and JONAS, J. J. Hot ductility of steels and its relationship to the problem of transverse cracking during continuous casting. International Materials Reviews. 1991. vol. 36, pp. 187-220.

[7] CARPENTER, K. R., KILLMORE, C. R. and DIPPENAAR, R. Influence of Isothermal Treatment on MnS and Hot Ductility in Low Carbon, Low Mn Steels. Metallurgical and Materials Transactions B. 2014. pp. 372-380.

[8] WANG, B., JI, Z., LUI, W., MA, J. and XIE, Z.. Application of Hot Strength and Ductility Test to Optimization of Secondary Cooling System in Billet Continuous Casting Proces. Journal of Iron and Steel Research, International, 2008. vol. 15, pp. 16-20.

[9] MINTZ, B. The influence of composition on the hot ductility of stells and the problem of transverse cracking. ISIJ International,, 1999. vol. 39; pp. 833-855.

[10] DJURIC, D., HÖLLER, C., OBERROITHER, M., SONDEREGGER, B., and SOMMITSCH, C.. In-situ Melting Procedure for Determination of the High Temperature Properties of Steels. Materials Testing. 2012. vol. 54 pp. 75-79.

[11] SUZUKI, H. G., NISHIMURA, S. and YAMAGUCHI, S. Characteristics of Hot Ductility in Steels Subjected to the Melting und Solidification. Transactions ISIJ. 1982, vol. 22, pp. 48-56. 
[12] KOZESCHNIK, E. MatCalc version 6.02 (Database mc_fe_2.059). http://matcalc.tuwien.ac.at/

[13] CANISCANOGLU, O., ILIE, S., BEAL, C. and SOMMITSCH, C. Hot Ductility Behavior of a Continuously Cast Steel During Solidification. STEELSIM 2013 The $5^{\text {th }}$ International Conference, Technical University of Ostrava, Czech Republic, 2013.

[14] HOFLEHNER C., SOMMITSCH, C., RAMSKOGLER, C., SIX, J. and ILIE, S. Influence of thermal history on the hot ductility of Ti-Nb microalloyed steels, ICS2018 $7^{\text {th }}$ international congress on science and technology of steelmaking, Venice, Italy 2018

[15] THOMAS, B.G, BRIMACOMBE, J.K and SAMARASEKERA, I.V. The formation of panel cracks in steel ingots: A state-of-the art review, ISS Transactions. 1986. vol. 7, pp. 7-20.

[16] ROBERTS, W., LEHTINEN, B. and EASTERLING, K. E. An in situ sem study of void development around inclusions in steel during plastic deformation. Acta Metallurgica.1976. vol. 24, issue 8, pp. 745-758.

[17] I-CHEN, W. and ARGON, A.S. Diffusive growth of grain-boundary cavities. Acta Metallurgica. 1981.vol. 29, issue 10, pp. 1759-1768.

[18] GREENWOOD, J. N., MILLER, D. R. and SUITER, J. W. Intergranular cavitation in stressed metals. Acta Metallurgica. 1954. vol. 2, issue 2, pp. 1715-1748

[19] LÜCKL, M., CALISKANOGLU, O., ILIE, S., SIX, J. and KOZESCHNIK, E. Impact of Surface Structure Control Cooling During Continuous Casting on Hot Ductility of Microalloyed Steel. steel research int. 2015. vol 87, issue 7, pp. 871-879. 